\title{
Neural correlates of colour categories
}

\author{
Elisabeth Fonteneau and Jules Davidoff \\ Department of Psychology, Goldsmiths College, University of London, London, UK \\ Correspondence to Dr Elisabeth Fonteneau, Department of Psychology, Goldsmiths College, University of London, Lewisham Way, \\ London SEI4 6NW, UK \\ Tel: + 44207078 5156; fax: + 44207078 5145; e-mail: e.fonteneau@gold.ac.uk
}

Received 27 April 2007; accepted I June 2007

\begin{abstract}
This study used an electrophysiological marker of visual detection to investigate adults' processing of colour difference. Event-related potentials were collected from the identical colour (green: $G_{0}$ ) presented as the frequent or infrequent stimulus within different colour contexts. Critically, we compared differences within the same colour category $\left(G_{0}\right.$ vs. green: $\left.G_{1}\right)$ to differences between colour categories $\left(G_{0}\right.$ vs. blue and $G_{0}$ vs. red). All differences showed a
\end{abstract}

change-related positivity with similar scalp distribution. It was, however, not simply the magnitude of colour difference that reduced the latencies of the change-related positivity. A change in colour category without a magnitude difference also reduced latency of the event-related potential. Thus, for the first time we report an independent neural correlate of a colour category. NeuroReport 18:1323-1327 (c) 2007 Lippincott Williams \& Wilkins.

Keywords: colour category, event-related potential, visual change detection, visual oddball

\section{Introduction}

Visual processing such as that carried out when searching for fruit [1] commonly involves detection of chromatic changes. The colour difference between fruit and leaves, however, is more than a simple hue difference; there is also a category difference. The category difference has behavioural consequences because stimuli crossing a colour boundary (between-category) are easier to distinguish than otherwise equidistant stimuli drawn from within the same category [2]. These origins of colour categories have been argued to be innate [2] or, alternatively, to derive from terms in the speaker's language [3]. Recent support for the latter hypothesis comes from a left hemisphere advantage for between-category colour discrimination [4] but behavioural studies cannot distinguish between effects due to changes to early level visual cortex and explanations that rely on postperceptual mechanisms [5].

To examine potential early visual correlates of colour categories, we employed an event-related potential (ERP) paradigm in a task of implicit colour categorization. With ERPs, categorization (e.g., animal vs. vehicle) can be detected as early as $80 \mathrm{~ms}$ [6] and as quickly as $120 \mathrm{~ms}$ for words, other objects [7], faces [7,8], with a similar time range for auditory phoneme categorization [9]. There have been no direct attempts to find such early ERP correlates of colour categorization though several studies have indirect data based on large colour differences. Kimura et al. [10] showed that colour change elicited two successive ERP correlates: a change-related positivity (CRP, 100-120 ms) followed by a negativity also called visual mismatch negativity (150-170 ms). They concluded that the CRP reflects the mismatch between the actual visual input and the preceding stimulus. Czigler et al. [11] used a smaller deviancy (pink-red) but found no differences. No studies, however, have collected ERPs that have contrasted between- category and within-category colour differences. Consequently, we cannot be sure of the interpretation of the visual change-related components with respect to categorical colour processing.

In our study, we examined colour differences using the oddball paradigm to define the temporal dynamics of neural correlates for colour categories. By equating colour differences in terms of discriminability [Commision Internationale de L'Eclairage (CIE) values], we can investigate whether a change in colour category by itself affects the neural response.

\section{Methods}

Participants

Twenty-five volunteers (13 women) participated for course credit or for cash. All were right-handed, English native speakers with normal or corrected-to-normal vision, 18-29 years old (mean age 20 years). Two participants were rejected after failing the off-line task (see details in procedure) and three for excessive electrical artefacts in their electroencephalogram (EEG). All participants gave written informed consent before participation.

\section{Experimental design and procedure}

The participants were required to detect infrequent cartoon characters embedded within blocks of sequentially presented colour patches and to press a response pad as quickly as possible. Each patch consisted of a square of colour (visual angle $25 \times 25^{\circ}$ from a viewing distance of $100 \mathrm{~cm}$ ). The stimuli used were derived from Munsell colours and kept lightness (Munsell value, $V=6$ ) and saturation (Munsell chroma, $C=10$ ) constant. Therefore, the only colour difference is due to hue. The oddball paradigm involved six different blocks in which a green $\left(G_{0}\right)$ 
colour (Munsell 2.5BG) was presented in different contexts: $\mathrm{G}_{0}$ as Standard and a red (R) colour (Munsell 5R) as deviant, $R$ as a standard and $G_{0}$ as deviant, $G_{0}$ as standard and a blue (B) colour (Munsell 4.8B) as deviant, B as a standard and $\mathrm{G}_{0}$ as deviant, $G_{0}$ as standard and a different green $\left(G_{1}\right)$ (Munsell 0G) as deviant, $\mathrm{G}_{1}$ as a standard and $\mathrm{G}_{0}$ as deviant.

Each block comprised 400 stimuli, 280 standard colours, 60 deviant colours and 60 cartoon pictures. Three colour comparisons were of interest: (i) large deviance betweencategory contrasts of $\mathrm{G}_{0}$ and $\mathrm{R}$ (called red: CIE, $\mathrm{L}^{*} \mathrm{u}^{*} \mathrm{v}^{*}$ colour space; $\Delta E=140$ ); (ii) small deviance between-category contrasts of $G_{0}$ and $B$ (called blue, $\Delta E=56$ ) and (iii) small deviance within-category contrasts between $G_{0}$ and $G_{1}$ (called green: again $\Delta \mathrm{E}=56$ ). The stimulus duration was $200 \mathrm{~ms}$ with an interstimulus interval randomized from 600 to $950 \mathrm{~ms}$ during which a central cross was presented (visual angle of $1 \times 1^{\circ}$ ) with the neutral background (7.5G, $V=9$, $C=1$ ).

Presentation order of blocks was balanced across participants. Before each block a small practice session was introduced. After the EEG recording, participants were asked to name each patch of colour presented in the same condition as in the experiment. Two participants named the $\mathrm{G}_{0}(2.5 \mathrm{BG})$ colour as blue and, therefore, were rejected from the average. No participant reported that they were aware that the study investigated colour.

\section{Electrophysiological recording}

EEG was recorded from $64 \mathrm{Ag}-\mathrm{AgCl}$ electrodes (http:// www.biosemi.com/) all referred to $\mathrm{Cz}$ (vertex) electrode (sampling rate of $512 \mathrm{~Hz}$, band pass of $0.1-134 \mathrm{~Hz}$ ). Vertical and horizontal electrooculograms were recorded between above and below the right eye and between two electrodes placed laterally to the left and right outer canthi, respectively. Critically, it is the response to $G_{0}$ that is used in every condition. The EEG was first divided into segments from $100 \mathrm{~ms}$ prestimulus to $600 \mathrm{~ms}$ poststimulus. Segments containing activity greater than $100 \mu \mathrm{V}$ were excluded from averaging. ERPs elicited by cartoon pictures and by the coloured squares following the pictures were discarded from the average. We computed the average for the $G_{0}$ colour separately for each stimulus type (standard, deviant) presented in different contexts $(R, B, G)$ for each participant. The resulting six sets of ERPs were rereferenced according to the average reference.

\section{Event-related potential analysis}

Mean amplitudes were quantified for consecutive time windows (TWs) of $40 \mathrm{~ms}$ duration between 120 and $280 \mathrm{~ms}$ following stimulus onset for nine different regions of interest (see Fig. 1). Three-way analyses of variances (ANOVAs) with stimulus type (standard, deviant), caudality (anterior, median, posterior) and hemisphere (left, right) as within-participant factors were carried out for each colour and TW. For midline sites, two-way ANOVAs were performed with factors stimulus type (standard, deviant) and caudality (anterior, median, posterior). The average amplitudes were then normalized and the GreenhouseGeisser correction was applied when evaluating effects with more than one degree of freedom in the numerator [12]. We report significant (corrected $P$ ) interactions including the factor stimulus type with post-hoc analyses using the Fisher LSD test. Furthermore, peak latencies and peak amplitudes have been defined on the difference wave (deviant standard) for each participant and each colour on four electrodes $(\mathrm{Fz}, \mathrm{AFz}, \mathrm{Oz}, \mathrm{Iz})$ within the $120-280 \mathrm{~ms}$ period. These measures were considered in two separate repeated measure ANOVAs with colour (R, B, G) and electrodes (anterior: two; posterior: two) as factors.

\section{Results}

\section{Behavioural performance}

Analysis of reaction times for detecting the cartoon pictures revealed no main effect of colour $[\mathrm{F}(2,38)=1.34, P=0.27)]$. Participants were as quick to detect the cartoons in the red block $(346.4 \pm 5.7 \mathrm{~ms})$ as compared with the blue block $(347.5 \pm 7.1 \mathrm{~ms})$ or the green block $(351.7 \pm 5.8 \mathrm{~ms})$. Accuracy was at ceiling.

\section{Red (large between-category) comparison}

The ANOVA revealed a significant interaction between stimulus type and caudality in the $120-160 \mathrm{~ms}$ TW for both analyses [Lateral: $\mathrm{F}(2,38)=8.7, P<0.003$; midline: $\mathrm{F}(2,38)=98.7, P<0.0001]$. The ERP for deviant $\mathrm{G}_{0}$ colour is more negative in anterior regions $(P<0.00001)$ and more positive in posterior regions $(P<0.001)$ compared with the ERP for standard $G_{0}$ colour (see Fig. 1, left).

\section{Blue (small between-category) comparison}

Results again revealed significant interactions between stimulus type and caudality for both analyses but now in the $160-200 \mathrm{~ms}$ TW [Lateral: $\mathrm{F}(2,38)=8.9, P<0.02$; midline: $\mathrm{F}(2,38)=11.6, P<0.001]$. The ERP for deviant $\mathrm{G}_{0}$ colour is more negative in anterior regions $(P<0.00001)$ and more positive in posterior regions $(P<0.0002)$ compared with the ERP for standard $G_{0}$ colour (see Fig. 1, middle).

\section{Green (small within-category) comparison}

The ANOVAs revealed significant interactions between stimulus type and caudality for the lateral analysis in the 160-200, 200-240 and 240-280 ms TWs $[\mathrm{F}(2,38)=6.8$, $P<0.006 ; \quad \mathrm{F}(2,38)=6.7, \quad P<0.004 ; \quad \mathrm{F}(2,38)=9.9, \quad P<0.0004$, respectively]. In each TW, the ERP for deviant $G_{0}$ colour is more negative in anterior regions $(P<0.004)$ and more positive in posterior regions $(P<0.01)$ compared with the ERP for standard $G_{0}$ colour. The midline analysis revealed a significant interaction between stimulus type and caudality only in the $240-280 \mathrm{~ms}$ TW $[\mathrm{F}(2,38)=5.7, P<0.007]$. Again, the ERP for deviant $G_{0}$ colour is more negative in anterior regions $(P<0.004)$ and more positive in posterior regions $(P<0.01)$ compared with the ERP for standard $\mathrm{G}_{0}$ colour (see Fig. 1, right).

To verify that the effects obtained for each colour comparison showed a similar distribution on the scalp, we ran a further repeated measure ANOVA using the mean amplitude of difference waves obtained within $120-160 \mathrm{~ms}$ for the red, $160-200 \mathrm{~ms}$ for blue and $200-240 \mathrm{~ms}$ for the green block. No significant effects were found in either lateral or midline analysis, indicating that the topography of each effect is identical for our three colour comparisons (see Fig. 1).

\section{Peak latency and peak amplitude analysis}

Results showed that peak latency on posterior $[\mathrm{F}(2,38)=17.9$, $P<0.0001]$ and anterior electrodes $[\mathrm{F}(2,38)=7.4, P<0.001]$ 

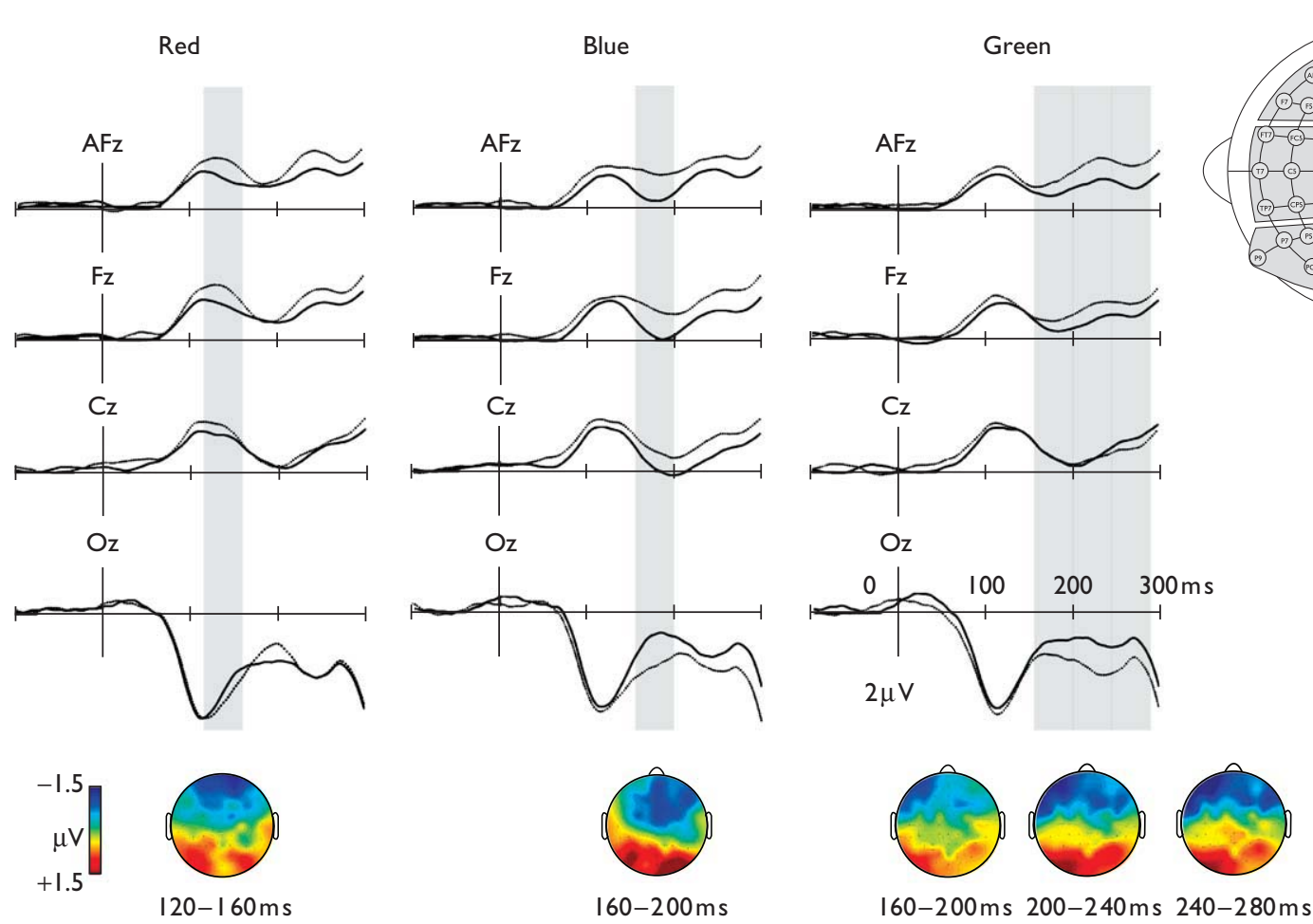

Standard

Deviant

Fig. I Grand-average ERPs for a subset of four electrodes for the standard and deviant stimuli for each colour context. In this, and in Fig. 2, negativity is plotted upwards and ERPs have been filtered at $10 \mathrm{~Hz}$ for the display. The grey bars correspond to the time windows with significant topographical differences between deviant and standard $\mathrm{G}_{0}$ colours. The scalp distributions at the bottom of the figure show difference maps (deviant minus standard) for each colour within the time windows showing significant topographical differences. The small negativity at Oz with a $200 \mathrm{~ms}$ peak latency (see Fig. I left) for the red comparison was not significant in the ROI analyses. ERP, event-related potential; ROI, regions of interest.
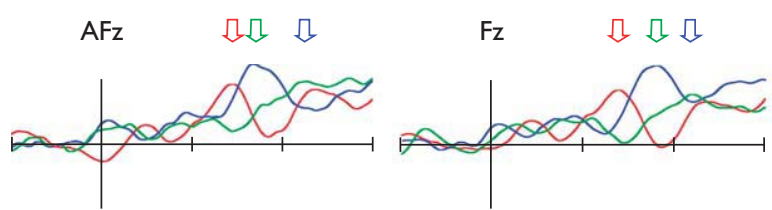

$\mathrm{Oz}$

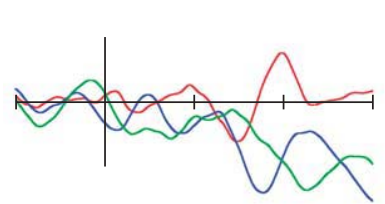

仓仓 仓
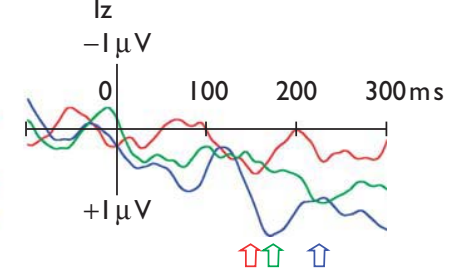

- Red - Blue — Green

Fig. 2 Difference waves (deviant minus standard) in each colour condition at four selected electrodes (anterior: $\mathrm{AFz}, \mathrm{Fz}$ and posterior: $\mathrm{Oz}$ and Iz). Arrows indicate the modulation of the change-related positivity (CRP) with the colour context.

vary as a function of the colours (see Fig. 2). On posterior sites, the peak latency of the red difference wave (161.4 ms) was shorter compared with blue $(195.3 \mathrm{~ms} ; P<0.0001)$ and green $(214.2 \mathrm{~ms} ; P<0.00001)$. Blue difference wave peak latency was also shorter compared with the green $(P<0.04)$.
On anterior electrodes the peak latency of the red difference wave $(174.5 \mathrm{~ms})$ was shorter compared with blue $(200.7 \mathrm{~ms}$; $P<0.02)$ and green $(217.5 \mathrm{~ms} ; P<0.0004)$, but not blue compared with green $(P<0.14)$. No significant effects were revealed for peak amplitude.

\section{Discussion}

We compared ERPs elicited by physically identical stimuli $\left(G_{0}\right)$ in three different contexts. In those contexts, the ERPs showed clear differences for CRPs related to both the magnitude and categorical status of colour deviancies. First, we consider effects of magnitude. Previous studies have only been able to find ERP modulation for large colour differences. In most of those studies (e.g. Refs. [11,13,14]), large colour differences resulted in significant effects in a very similar TW to those found in the red context (i.e., 120$160 \mathrm{~ms})$. This study was, however, able to find ERP differences not only for a large colour difference (red context) but also for a smaller colour difference (blue context). The smaller contrast resulted in an ERP delayed to a window of $160-200 \mathrm{~ms}$. Thus, the colour difference is not reflected in differences in peak amplitude but in peak latency. CRPs reflect feature change for orientation [15] and spatial frequency [16]. Similarly, we wish to argue for colour features that, for both magnitude and categorical deviancies, CRPs reflect processes activated when the deviant stimulus 
is compared with a sensory memory trace. An alternative position would be that the CRP is a manifestation of exogenous P1/N1 components and thus could be explained by the refractoriness hypothesis [17]. Our data, however, give only latency and not amplitude differences when comparing large and small deviancies; therefore, they do not support that alternative position.

The second advance in understanding neuronal correlates of colour difference comes from the comparison between the between-category (blue context) and within-category (green context) conditions. Those two conditions compared contrasts of equal physical magnitude but they did not produce equivalent effects in ERP. The peak latency for the betweencategory comparison at $195 \mathrm{~ms}$ was significantly quicker than the $214 \mathrm{~ms}$ peak latency for the physically equal withincategory condition. Here we have the first evidence for neural correlates of colour differences that reflect a categorical change, that is, between-category stimuli look more different than within-category stimuli [18]. Differences for the between-category (blue context) appeared during the time window (160-200 ms) corresponding to the N1 in the visual ERP sequence suggesting that colour category affects visual processing before completion of perceptual analysis. The data from within-category deviancy (green context) show ERPs extended over an even longer time window (160-280 ms) compatible with a psychologically compressed colour space [19] and hence more difficult discrimination.

Concerning categorization, we draw attention to four other aspects of our data. The first is to note that categorization as simple as colour appears to operate with the same temporal dynamics as other apparently more complex visual categorization tasks [7]. The second is to comment further on the reduction of the latency for the CRP [10]. On one view, categorization is seen as an extra process carried out after exemplar identification [20]. On that view, the extra processing required for categorization ought to have delayed rather than accelerated processing. An alternative view sees object detection and object categorization as taking place concurrently during visual recognition [6]; it is within-category discrimination that requires extra processing. Our data support that latter view as withincategory discrimination revealed the longest latencies.

The third aspect of our data concerning categorization relates to attentional processes. In our study, comparisons that result in CRPs do so without attention focussed on colour. No observer reported that the task concerned colour and there is indirect evidence for that introspection from our ERP data. In other research, the ERP components indexing selective information processing to specific visual features (e.g., colour or spatial frequency) include a frontal selection positivity, an occipital negativity known as selective negativity and a centro-frontal negativity [21]. None of these attention selection effects, however, showed the typical distribution - posterior positivity depicted for the CRP. It is then unlikely that our CRP reflects purely attentional processes. Indeed, Kimura et al. [14] have previously showed that the CRP component is elicited irrespective of whether or not the stimulus feature change is task relevant.

We, fourthly, comment on the relationship between our findings and the proposed left lateralized basis of colour categorization $[4,22,23]$, including the role of language in colour categorization [24]. One issue concerns the minimal effects of laterality within our data. No laterality effects emerged in the contrast between colours not even for those categorically different (red vs. green and blue vs. green). Our data thus do not provide evidence for an early level locus for the recent behavioural findings of left hemisphere superiority for colour categories [4] though it should be noted that a replication [22] found a categorical colour effect for both hemispheres. A clear and important difference between our study and those that have found lateralized effects of colour categories is that our task is implicit and is less likely to involve labelling. Our data would indicate that the left hemisphere advantage for categorical colour discrimination reflects an on-line top-down influence of colour labels from language areas as seen in previous categorization studies of pictorial stimuli [25] and is not due to a lateralized neural substrate in occipital cortex. In this respect, we note an aphasic patient who showed no ability to categorize colours in an explicit task but, nevertheless, intact colour categories in an implicit task [24]. Therefore, even if colour categories are initially derived from the colour terms of a speaker's language [3], the changes to colour appearance would appear to have been effected not in language areas but at a site within the visual cortex.

\section{Conclusion}

We have demonstrated that both colour difference and colour categorical information are used during passive discrimination of visual events. Colour categorization takes place rapidly and was observed as early as $160 \mathrm{~ms}$ following stimulus onset. Indeed, colour categorization appears to take priority within visual analysis because the latency of an ERP correlate was reduced compared with that of an otherwise equal colour discrimination.

\section{Acknowledgement}

This research was funded by EC grant no. 012984 for Stages in the Evolution and Development of Sign Use (SEDSU).

\section{References}

1. Mollon JD. 'Tho' she kneel'd in that place where they grew...'. The uses and origins of primate colour vision. J Exp Biol 1989; 146:21-38.

2. Bornstein $\mathrm{MH}$, Korda NO. Discrimination and matching within and between hues measured by reaction times: some implications for categorical perception and levels of information processing. Psychol Res 1984; 46:207-222.

3. Davidoff J. Language and perceptual categories. Trends Cogn Sci 2001; 5:382-387.

4. Gilbert AL, Regier T, Kay P, Ivry RB. Whorf hypothesis is supported in the right visual field but not the left. Proc Natl Acad Sci USA 2006; 103:489-494.

5. Pilling M, Wiggett A, Ozgen E, Davies IRL. Is color categorical perception really perceptual? Memory Cogn 2003; 31:538-551.

6. VanRullen R, Thorpe SJ. The time course of visual processing: from early perception to decision-making. J Cogn Neurosci 2001; 13:454-461.

7. Schendan HE, Ganis G, Kutas M. Neurophysiological evidence for visual perceptual categorization of words and faces within $150 \mathrm{~ms}$. Psychophysiology 1998; 35:240-251.

8. Jacques C, Rossion B. The speed of individual face categorization. Psychol Sci 2006; 17:485-492.

9. Winkler I, Kujala T, Tiitinen H, Sivonen P, Alku P, Lehtokoski A, et al Brain responses reveal the learning of foreign language phonemes. Psychophysiology 1999; 36:638-642.

10. Kimura M, Katayama J, Murohashi H. Probability-independent and -dependent ERPs reflecting visual change detection. Psychophysiology 2006; 43:180-189. 
11. Czigler I, Balazs L, Winkler I. Memory-based detection of task-irrelevant visual changes. Psychophysiology 2002; 39:869-873.

12. Rösler F, Heil M, Glowalla U. Monitoring retrieval from long-term memory by slow event-related brain potentials. Psychophysiology 1993; 30:170-182.

13. Czigler I, Weisz J, Winkler I. ERPs and deviance detection: visual mismatch negativity to repeated visual stimuli. Neurosci Lett 2006; 401:178-182.

14. Kimura M, Katayama J, Murohashi H. Positive difference in ERPs reflects independent processing of visual changes. Psychophysiology 2005; 42: 369-379.

15. Fu S, Fan S, Chen L. Event-related potentials reveal involuntary processing of orientation changes in the visual modality. Psychophysiology 2003; 40:770-776.

16. Kimura M, Katayama J, Murohashi H. An ERP study of visual change detection: effects of magnitude of spatial frequency changes on the change-related posterior positivity. Int J Psychophysiol 2006; 62:14-23.

17. Kenemans JL, Jong TG, Verbaten MN. Detection of visual change: mismatch or rareness? NeuroReport 2003; 14:1239-1242.

18. Kay P, Kempton W. What is the Sapir-Whorf hypothesis? Am Anthropologist 1984; 86:65-78.
19. Goldstone R. Influences of categorization on perceptual discrimination. J Exp Psychol: General 1994; 123:178-200.

20. Grill-Spector K, Kanwisher N. Visual recognition. Psychol Sci 2005; 16:152-160.

21. van der Stelt O, Kok A, Smulders FT, Snel J, Boudewijn Gunning W. Cerebral event-related potentials associated with selective attention to color: developmental changes from childhood to adulthood. Psychophysiology 1998; 35:227-239.

22. Drivonikou GV, Kay P, Regier T, Ivry RB, Gilbert AL, Franklin A, Davies IR. Further evidence that Whorfian effects are stronger in the right visual field than the left. Proc Natl Acad Sci USA. 2007; 104:1097-1102.

23. Ikeda T, Osaka N. How are colors memorized in working memory? A functional magnetic resonance imaging study. NeuroReport 2007; 18 111-114

24. Roberson D, Davidoff J, Braisby N. Similarity and categorisation neuropsychological evidence for a dissociation in explicit categorisation tasks. Cognition 1999; 71:1-42.

25. Kiefer M. Perceptual and semantic sources of category-specific effects: event-related potentials during picture and word categorization. Memory Cogn 2001; 29:100-116. 